\title{
TRASHUMANCIA Y PASTOS DE AGOSTADERO EN LAS SIERRAS SORIANAS DURANTE EL SIGLO XVIII
}

\author{
EMILIO PÉREZ ROMERO \\ Universidad Alfonso X El Sabio
}

\begin{abstract}
RESUMEN
El propósito de este articulo es doble: por un lado, presentar una visión general del régimen de aprovechamiento de pastos de verano y de la estructura de la propiedad del ganado trashumante en las sierras sorianas a mediados del siglo XVIII, $y$, por otro, analizar la evolución que ambos siguieron durante la segunda mitad de la centuria, prestando especial atención a las repercusiones que alli tuvo la legislación sobre pastos concejiles del reinado de Carlos III. A este respecto, ofrecemos algunos datos que avalan la hipótesis de que dicha legislación fue el factor desencadenante de una primera crisis de la trashumancia serrana, que se adelantó en varias décadas a la crisis general de finales de siglo.
\end{abstract}

\section{ABSTRACT}

The objective of this article is twofold. First, it aims to present a general overview of the exploitation regime of pastures during summer time, as well as the 18th-century ownership structure of the migrating cattle in the Sorian mountains. Second, it analyses the evolution during the second half of the century, paying special attention to the effects that the legislation had on the municipal pastures during the reign of Carlos III. The evidence supports the hypothesis that the legislation was the factor which triggered the first crisis in the trasbumancia, that preceded the general crisis at the end of the century by several decades.

\section{INTRODUCCIÓN}

El estudio de la trashumancia desde la perspectiva de los agostaderos es aún incipiente ${ }^{1}$. No obstante, por lo que se refiere a las sierras sorianas, ya

' La principal y casi unica excepción, hasta hace poco, la constituia el caso de Segovia: García Sanz (1977).

Retista de llistoria Económico

Ano XIV. Inverno $1996 . N^{\prime \prime} 1$ 
contamos con excelentes trabajos referidos a los siglos XV y XVI ${ }^{2}$. Este articulo pretende avanzar en la misma linea de investigación, extendiendo el anälisis al siglo XVIII, otro período clave en la historia de la trashumancia castellana. Para ello, nos centraremos en el caso de la Tierra de Soria, aunque en las páginas que siguen también se hacen referencias a las de Ágreda, Yanguas y San Pedro Manrique. Entre estas cuatro jurisdicciones reunian, a mediados del siglo xviII, casi medio millón de cabezas de ganado lanar trashumante, es decir, en torno al 59 por 100 de todas las registradas en la antigua provincia de Soria ${ }^{3}$. Los pastos, en su mayor parte comunales, constituian alli el componente fundamental del terrazgo. En contrapartida, la superficie cultivada era en todos los casos muy pequeña: sólo un 16 por 100 en la Tierra de Yanguas, un 21,5 por 100 en la de San Pedro Manrique y un 24 por 100 en la de Soria. En esta última, según nuestros cálculos, la ganadería aportaba en torno al 40 por 100 del producto bruto agrario 4 .

\section{PASTOS DE AGOSTADERO: TIPOLOGIA Y RÉGIMEN DE APROVECHAMIENTO}

La trashumancia soriana, al menos la que se practicaba desde las tierras situadas al sur de la línea de cumbres del Sistema Ibérico, fue siempre una trashumancia inversa, es decir, de ganado cuya propiedad radicaba en las mismas sierras o en las tierras llanas de su periferia. Esto era así en la medida en que a efectos de aprovechamiento de pastos las tierras sorianas constituian un espacio cerrado - $\mathrm{e}$ internamente fragmentado- a los ganaderos no avecindados en ellas. La vecindad era, con pocas excepciones, condición sine qua non para acceder a los pastos de cada una de las jurisdicciones, en general herederas de las comunidades medievales de villa y tierra. Algunas, no obstante, practicaban un régimen de tolerancia reciproca que permitia el libre movimiento de los rebaños entre sus respectivos términos «de sol a sol». La vecindad estaba sujeta al cumplimiento de ciertos requisitos. Asi, en la Tierra de Soria se exigia mantener casa abierta en la ciudad o en alguno de los pueblos de su jurisdicción y que la familia residiese en ella durante la mayor parte del año. Naturalmente, los privilegios mesteños garantizaban el derecho de paso al

\footnotetext{
2 Cabe destacar, como estudios de conjunto, Diago (1993a) y Diez Sanz (1995).

- Archivo Historico Nacional (en adelante, AHN), Hacienda, libro 7489 (Mapa H del Catastro de Ensenada).

- Pérez Romero (1995), pp. 30-32. En este trabajo se desarrollan con más detalle algunas de las cuestiones a las que se refiere el presente articulo.
} 
ganado que en sus desplazamientos tenía que cruzar territorios ajenos, aunque sólo fuese durante el tiempo imprescindible para atravesarlos s.

Esta cerrazón frente al exterior contrastaba con la vigencia, dentro de cada tierra, del principio de comunidad general o universal de pastos, que facultaba a todos sus vecinos, con independencia de en qué lugar residiesen dentro de la misma, a usufructuar todos los pastos de su continente, unos, los baldios, de forma permanente y otros, los sujetos a acotamiento concejil, fuera de los pe. riodos en que permanecian vedados. Al margen de la comunidad de aprovechamientos sólo quedaban, por concesión real, algunas dehesas y montes privilegiados, y los términos redondos que desde la Baja Edad Media habían constituido distintos miembros de la oligarquia urbana. Fuera de estos últimos, apenas habia pastos de propiedad privada en las sierras sorianas.

Por lo que se refiere al alcance de la comunidad jurisdiccional de pastos, es preciso distinguir entre baldíos y términos despoblados, por un lado, y pastos concejiles, por otro. En efecto, cada pueblo disponia de pastos -dehesas boyales, montes vecinales y rastrojeras- que en determinadas épocas del año podia acotar y reservar, en exclusiva, al ganado de la localidad y en los que, por tanto, la comunidad jurisdiccional de aprovechamientos sólo regia de forma intermitente. Se trataba, no obstante, de una mera preferencia de uso, ya que en la Tierra de Soria el dominio de los concejos rurales sobre sus bienes comunes y su capacidad para regular ciertos derechos vecinales, como la derrota de mieses, estaban limitados por las prerrogativas que el Ayuntamiento de la ciudad conservaba, desde época medieval, sobre las que inicialmente habian sido las aldeas de su alfoz. Lo cual, en materia de aprovechamiento de pastos, tenía su importancia, dado el control que los grandes ganaderos de la nobleza urbana ejercian sobre el concejo soriano. Como contrapeso al poder del Ayuntamiento de Soria, la Junta de la Universidad de la Tierra, presente como institución diferenciada cuando menos desde el siglo xv, se afianzó en la segunda mitad del xvill en su papel de portavoz y representante de las comunidades rurales 6 .

\footnotetext{
'Cuando menos desde el siglo $\mathrm{X} v$, a los rebaños yangüeses y cameranos no se les permitia emplear más de siete dias en atravesar la Tierra de Soria: Archivo Histórico Provincial de Soria (en adelante, AHPSo), 3459, Universidad de la Tierra (en adelante, UT), 115.

- La Junta de la Universidad estaba compuesta por un fiel, un procurador general y cinco procuradores de sexmo, con mandato bianual. Todos los vecinos de los 150 pueblos de la Tierra eran electores y, en teoria, elegibles como procuradores. Éstos, a su vez, designaban al fiel, cargo que recayo invariablemente en miembros de la nobleza urbana hasta 1751 , cuando la Junta consiguio la aprobación por el Consejo de Castilla de un reglamento que convertia automáticamente en fiel al procurador general saliente. El fiel y el procurador general eran, en calidad de representantes de la Tierra, miembros natos del Ayuntamiento de Soria.
} 
En cuanto a los baldíos, sus pastos eran de común aprovechamiento para todos los vecinos de la jurisdicción, sin restricciones temporales ni discriminación alguna en función del lugar de residencia. Así lo establecia el Fuero, y tanto el Ayuntamiento de Soria como la Junta de la Universidad velaban por su integridad, persiguiendo - bien es cierto que con distinto celo y éxito, según el momento y el infractor - a quienes trataban de apropiárselos mediante acotamientos o roturaciones. Esta situación de facto se consolidó a partir de 1739, cuando la Corona cedió a los vecinos de ciudad y Tierra, a cambio de una compensación económica, el dominio que pudiera corresponderle sobre los baldios sorianos.

Todo el espacio que aqui consideramos constituia en el vocabulario mesteno, de forma indiferenciada, «las sierras», pero lo cierto es que encerraba una clara dualidad geográfica y económica, pudiendo distinguirse, por un lado, las sierras propiamente dichas, con un medio físico de montaña, poco apto para la práctica de la agricultura y, por lo tanto, con una economia históricamente orientada hacia las actividades ganaderas y forestales, y, por otro, al sur de éstas, las tierras llanas del valle del Duero con un paisaje caracterizado por los campos de cereal. Algunas jurisdicciones, como las de San Pedro Manrique y Yanguas, eran básicamente serranas, en tanto que otras, como la de Soria, al. bergaban en su interior la división entre comarcas serranas y tierras llanas.

La distinta orientación económica de cada una de estas zonas se reflejaba en la también diferente función que, tradicionalmente, habian desempeñado los pastos en una y otra. Los extensos baldios de las sierras, sin apenas otra utilidad que el pastoreo estival, eran el núcleo original de la trashumancia soriana, en tanto que los pastos concejiles de las tierras llanas, dedicadas a la producción de cereal en régimen de «año y vez», habían estado, primariamente, subordinados a las necesidades de las explotaciones campesinas: los de las dehesas para el mantenimiento del ganado de labor y los de rastrojeras, barbecheras y entrepanes - $y$, en su caso, los montes - para el del ovino estante y otro ganado doméstico. El acotamiento temporal que los concejos podian ha. cer de sus dehesas, montes y rastrojeras estaba destinado, precisamente, a preservar esta función. Así, las dehesas boyales de los pueblos sorianos recibian la denominación de martiniegas o sanmartiniegas por permanecer acotadas, en beneficio del ganado de labor de sus respectivos vecindarios, desde primeros de mayo hasta San Martin (11 de noviembre), coincidiendo con la estancia de los rebaños trashumantes en las sierras. En las rastrojeras había funcionado un régimen parecido hasta finales del siglo XVI.

No obstante, en el siglo Xvin hacia tiempo que la actividad trashumante habia desbordado las comarcas serranas, entendidas en sentido estricto, tanto 
por lo que se refiere a la localización de la propiedad del ganado como a la definición de zonas de pastos de verano. Una y otros se habian extendido, desplazando su centro de gravedad hacia el sur, hasta penetrar profundamente en las comarcas cerealistas del valle del Duero. Así, en el momento de la confección del Catastro, la mayoria de los pueblos de la Tierra de Soria (cuando menos, 122 de 150) arrendaban sus rastrojeras y algunos, también, sus dehesas boyales y otros pastos acotados como agostaderos para el ganado trashumante. Arrendamientos parecidos se practicaban en las jurisdicciones vecinas ${ }^{7}$. El trasfondo de este fenómeno hay que buscarlo en la saturación pecuaria que las sierras experimentaban durante el verano. A mediados de siglo, la cabaña trashumante arrojaba densidades superiores a las 100 cabezas por kilómetro cuadrado en la Tierra de Soria y de alrededor de 400 en las de San Pedro Manrique y Yanguas ${ }^{8}$. Nos consta que ya en el primer tercio del Setecientos, antes, pues, de que se alcanzasen los máximos de ocupación ganadera, las mayores cabañas sorianas se veian obligadas, pese a su excelente posición en cuanto a acaparamiento de pastos, a enviar una parte del ganado a herbajar en verano fuera de la jurisdicción: al Ducado de Medinaceli, a las villas de Retortillo y Borobia o, más al sur, a tierras de Atienza ${ }^{9}$. Del mismo modo, en las décadas finales de la centuria, algunos rebaños sorianos agostaban en zonas tan alejadas como Vizcaya o las montañas de León ${ }^{10}$. Por otro lado, al ganado trashumante, es decir al que invernaba en Extremadura, Andalucía o La Mancha, hay que añadir el riberiego, que sumaba unas 34.000 cabezas a mediados de siglo ${ }^{11}$.

Los rebaños trashumantes arribaban a las tierras sorianas durante el mes de mayo y permanecian en ellas cuatro meses y medio, más o menos. A su llegada, la mayoria se dirigia directamente a los baldios de las sierras, donde pastaban las ovejas hasta que, a mediados de junio, bajaban para ser esquiladas en las instalaciones que, a tal efecto, tenían los grandes ganaderos en distintos tér. minos particulares, operación que se prolongaba hasta San Juan o San Pedro ( 24 y 29 de junio, respectivamente). Concluida la esquila, los rebaños retornaban a los baldios serranos o se mantenian en las hojas de barbecho hasta que,

\footnotetext{
Por lo que se refiere a la Tierra de Yanguas, Alcalde (1993), t. I, p. 451. Para el Ducado de Medinaceli, AHN, Consejos, leg. 27938, exp. 8.

${ }^{8}$ Estos calculos se basan en los datos del Catastro de Ensenada: Pérez Romero (1995), p. 146, y Alcalde (1993), t. I, pp. 452 y 462.

AHN, Consejos, leg. 42920.

10 AHN, Consejos, leg. 29374, pieza 4.

"Recibia la denominación de riberiego el ganado que invernaba en el valle del Ebro, en tierras de Aragón, Navarra y La Rioja, procedente del partido de Ágreda o de los pueblos más orientales de la Tierra de Soria.
} 
alzada la cosecha, podian entrar a pastar en los rastrojos que tenian arrendados. Si bien la fecha de la siega variaba en función de la latitud, retrasándose conforme aumentaba ésta, lo normal era que hacia Santiago ( 25 de julio) se hubiese completado en toda la Tierra. El acotamiento de los rastrojos y, por lo tanto, el aprovechamiento privativo de los mismos que arrendaban los ganaderos duraba hasta "Nuestra Señora de agosto» (fiesta de la Asunción, 15 de agosto), salvo en los pueblos más septentrionales, en los que finalizaba el día de «Nuestra Señora de septiembre» (fiesta de la Natividad de la Virgen, 8 de septiembre). No obstante, era frecuente que el Ayuntamiento de Soria, a petición de ganaderos y concejos, prorrogase los acotamientos en toda la jurisdicción hasta fines de agosto o comienzos de septiembre. Además, nada impedia a los ganaderos mantener las merinas en los rastrojos una vez levantada la veda, compartiendo el pasto que todavia quedara con el ganado de los demás vecinos, hasta el mismo momento de emprender el retorno a extremos, hacia San Mateo (21 de septiembre). Evidentemente, la extensión de las rastrojeras, unas 30.000 hectareas, era muy inferior a la que ocupaban baldios y barbecheras, pero su pasto era de calidad superior y más homogénea. Así, aunque el pasto de los rastrojos fuese siempre complementario del que proporcionaban baldios y barbechos, su incorporación a los agostaderos no sólo aumentó la cabida de éstos sino que también mejoró la alimentación del ganado. Los entendidos aseveraban que el ganado que pastaba en las rastrojeras «se aventaja[ba] mucho más assi en carnes como en lanas a el que an$\mathrm{da}[\mathrm{ba}]$ por los valdios sin tener destino particular» ${ }^{12}$, al tiempo que se fortalecia justo en vísperas de su puesta en camino, canada abajo, hacia los invernaderos. Con todo, hay que subrayar que, aun después de la generalización del arrendamiento de rastrojeras, las merinas que agostaban en las sierras sorianas se mantenian durante la mayor parte del verano consumiendo pastos gratuitos.

Todo apunta a que la incorporación masiva de los pastos concejiles a los agostaderos se habia producido en el tránsito del siglo XVI al XVII ${ }^{13}$, cuando, en medio de una difícil coyuntura, las comunidades campesinas, debilitadas por las ventas de baldíos y la introducción del impuesto de millones, cedieron a la presión de los grandes ganaderos trashumantes, abriendo a sus rebaños pastos que, hasta entonces, les habian estado vedados. El resultado fue, si no el inicio, si la generalización del arrendamiento de rastrojeras y, en menor me-

12 AHN, Consejos, leg. 26846, pieza 2, f. 26.

is Sobre el aprovechamiento de los pastos serranos en los siglos xv y xvI, vid. Diago (1990), (1993b) y (1994b). 
dida, de dehesas boyales como agostaderos ${ }^{14}$. Esta fue en las tierras sorianas una de las principales manifestaciones 15 del amplio movimiento de privatización de bienes y aprovechamientos comunales que afectó al agro castellano entre finales del siglo XVI y comienzos del XVII ${ }^{16}$.

Con el arriendo de la rastrojera, el concejo transferia al arrendatario el derecho al aprovechamiento privativo de la misma que, en principio, correspon. dia a la comunidad vecinal durante el periodo en que aquélla podía ser vedada. Una vez concluido el acotamiento quedaba de nuevo, hubiese o no arrendamiento, inmersa en el régimen general de comunidad de pastos. La base legal de los arrendamientos radicaba, pues, en el derecho que asistía a los pueblos para acotar temporalmente los rastrojos. A este respecto, la costumbre desde la Baja Edad Media había sido que los pueblos vedasen los «pagos de panes» hasta el 15 de agosto, con una triple finalidad: salvaguardar las mieses del ganado hasta la recogida de los haces, facilitar el espigueo a los vecinos más pobres y reservar durante algún tiempo el pasto del rastrojo al ganado de la localidad, que, de paso, estercolaba la tierra que quedaria en barbecho al año siguiente, tras ser alzada en primavera. La organización del terrazgo en hojas que exigía esta práctica ya habia tomado forma en el siglo xvI.

La capacidad de los concejos para acotar las rastrojeras (junto con entrepanes, barbechos y otros pagos) fue cuestionada por los alcaldes entregadores a finales del siglo xvı y, nuevamente, a mediados del xvI, con el evidente propósito de incluirlas, sin coste alguno, dentro de los espacios de «paso y pasto común» para el ganado trashumante, alegando que no se contaban entre las "cosas vedadas». La Chancillería de Valladolid resolvió en ambas ocasiones a favor de los pueblos, confirmando su derecho a acotar y vedar los rastrojos. No obstante, la ejecutoria expedida en tal sentido por la Chancilleria en 1593 (y ratificada en 1649) ${ }^{17}$, lejos de ser utilizada por los pueblos para excluir definitivamente al ganado trashumante de sus pastos, constituyó el punto de partida para la difusión de los arrendamientos, operándose por esta vía una importante reasignación de recursos en beneficio de las explotaciones trashumantes. Los arrendamientos contribuyeron a subordinar las pequeñas explotaciones agricolas, mayoritarias en el campo soriano, a las ganaderas, al tiempo que, dentro de éstas, favorecía a las mayores, las más ne-

\footnotetext{
it Los contratos de arrendamiento que ha localizado Diez Sanz (1995), pp. 126.129, son todos posteriores a 1594. No obstante, los hay de fechas anteriores: Diago (1994b), p. 49.

15 Otra fue la venta de baldios. Sobre su desarrollo y consecuencias en la Tierra de Soria, vid el reciente y completo estudio de Diez Sanz (1995), pp. 142-178.

16 Garcia Sanz (1980), Llopis (1986).

17 AHPSo, 3435, UT, 1 y 2.
} 
cesitadas de pastos adicionales a los que podian encontrar gratis en los baldios y las que mejor podian afrontar el pago de los mismos, aunque su precio nunca fue muy elevado. Lo cierto es que algunos ganaderos se apropiaron, por esta via, de unos pastos enormemente apreciados y que lo hicieron, además, mediante un mecanismo, el arriendo, que les permitia excluir de su aprovechamiento tanto a los labradores, en su condición de propietarios de pequeños hatos estantes, como a otros ganaderos trashumantes de menor entidad, cuyos rebaños quedaron circunscritos a los baldios. Los ganaderos valoraban enormemente la seguridad, la estabilidad y la exclusividad en el aprovechamiento de pastos. En este sentido, en las sierras, la vecindad les garantizaba gratuitamente las yerbas de los baldios y mediante los arrendamien. tos, consolidados por la posesión, incorporaron de forma estable a su «espacio vital» los pastos concejiles. Este doble mecanismo de restricción de la competencia externa e interna les daba, en el siglo xvin, un completo «dominiow sobre los pastos sorianos, reforzado por su control sobre las principales instituciones de poder local y su condición, en muchos casos, de propietarios multifundistas.

La intrusión del ganado trashumante en los pastos concejiles alteró el sistema de aprovechamientos comunales que garantizaba la pervivencia y reproducción de las pequeñas explotaciones campesinas: al desvirtuarse la función de la derrota de mieses, se limitó, cuando no se redujo, su capacidad para mantener ganado estante, sobre todo en las zonas cerealistas donde menos terreno quedaba sin roturar y, por lo tanto, más difícil era encontrar pastos alternativos próximos a los que recurrir durante la estancia de las merinas. $\mathrm{A}$ este respecto, los efectos negativos se produjeron más que por una disminu. ción en el aporte y disponibilidad de abono (en cuanto el ganado trashumante sólo podía suplir estacionalmente al estante en el estercolado de los barbechos), por la reducción o desaparición, según los casos, del complemento económico que los esquilmos del ganado estante aportaban a las economías familiares.

No obstante, es preciso matizar esta primera aproximación a las repercusiones que el arrendamiento de los rastrojos tenía sobre las economías campesinas. Primero porque los efectos negativos no eran generales, en la medida en que algunos pueblos podían desviar su ganado a los baldíos, reservarse cotos en las rastrojeras o negociar con los arrendatarios la introducción en las mismas de una parte del ganado de los vecinos (sobre todo, el de labor en los casos en que la dehesa boyal era insuficiente). Y segundo, porque de los arrendamientos también se derivaban algunas ventajas. La fundamental era que evitaban o aliviaban, reduciendo su número y cuantia, las derramas que los con- 
cejos, a falta de otros ingresos, se habrían visto obligados a hacer entre los vecinos para sufragar gastos colectivos de carácter ordinario, como la reparación de caminos y acequias, o hacer frente a contingencias y calamidades imprevistas, como la falta de grano para sembrar tras una mala cosecha. Sin duda, fue la imposibilidad de atender estas necesidades con las rentas de los bienes de propios, muy escasos en los pueblos sorianos, el factor que, desde la perspectiva campesina, más contribuyó a justificar la introducción y el mantenimiento de los arriendos. Los testimonios a este respecto son abundantes e inequívocos. De hecho, a mediados del siglo xvIII, los pueblos de la Tierra de Soria percibian, en conjunto, unos 70.000 reales anuales por el alquiler de agostaderos, una cantidad muy superior a la que generaban sus propios (véase - cuadro 1). Para muchos concejos esta era su principal fuente de ingresos. Pero, además, al regular y ordenar el acceso del ganado trashumante a los rastrojos, los arriendos libraban a los concejos de los conflictos y litigios que, en su ausencia, provocaban recurrentemente las intrusiones, accidentales o deliberadas, de las merinas en las rastrojeras. Los arrendamientos garantizaban, asi, que el ganado no dañase las mieses a punto de ser segadas o los haces amontonados en los campos, como ocurria con frecuencia cuando el pastoreo se realizaba subrepticiamente y sin control. Alli donde había un arrendatario habia un responsable al que pedir cuentas, cuyos pastores se cuidaban, además, de que otros rebaños no entrasen en unos pastos, por lo general, pagados por adelantado.

\section{CUADRO 1}

Composición de los ingresos concejiles en la Tierra de Soria (c. 1752)

\begin{tabular}{|c|c|c|}
\hline Concepto & $\begin{array}{c}\text { Importe anual } \\
\text { (reales) }\end{array}$ & 96 \\
\hline Propios rústicos .... & 41.629 & 31,79 \\
\hline 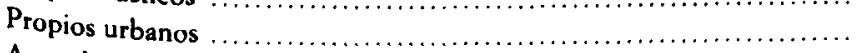 & 6.951 & 5,31 \\
\hline Arrendamiento de rastrojeras y otros pastos concejiles ... & 70.393 & 53,75 \\
\hline 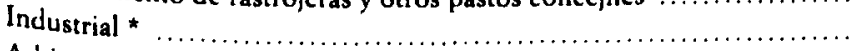 & 2.002 & 1,53 \\
\hline Arbitrios, derechos y tasas $\ldots \ldots$ & 9.987 & 7,62 \\
\hline Toral ............... & 130.962 & 100,00 \\
\hline
\end{tabular}

* Producto de tierras de particulares, casi siempre instituciones eclesiasticas, tomadas en arriendo por algunos concejos.

Ftente: AHPSo, Catastro de Ensenada, asientos de los concejos en los libros de lo real. 
$\mathrm{Si}$ a finales del siglo xvı se generalizan los arrendamientos de rastrojeras, todo indica que durante el siglo XVII se consolidaron mediante la aplicación a los mismos de la posesión mesteña, de modo que en el siglo XVIII, como revelan los contratos que se conservan en los protocolos notariales y el mismo Catastro de Ensenada, los agostaderos concejiles estaban acaparados por las principales cabañas sorianas ${ }^{18}$. La posesión, por otro lado, había permitido a algunos ganaderos de jurisdicciones vecinas burlar la exigencia de vecindad y hacerse con pastos de verano en la Tierra de Soria, la más extensa del ámbito serrano. En resumen, entre finales del xvI y el XVII, los ganaderos trashumantes instrumentalizaron en su beneficio, sin necesidad de cambiarlas, las normas que desde la Edad Media habian regulado en las sierras el aprovechamiento de pastos, eso si, a costa de desvirtuar su sentido y función, en perjuicio de las explotaciones campesinas.

\section{ESTRUCTURA DE LA PROPIEDAD DEL GANADO TRASHUMANTE}

A mediados del siglo XVIII, y todo indica que siempre había sido así ${ }^{19}$, la propiedad del ganado trashumante estaba notablemente concentrada en las sierras sorianas. En la Tierra de Soria, el 7 por 100 de los propietarios, todos con cabañas superiores a las 1.000 cabezas, poseian el 78 por 100 del lanar trashumante. Los que contaban con más de 5.000 cabezas, siendo menos del 3 por 100 de los propietarios, reunian el 42 por 100 de las merinas. En otras jurisdicciones serranas, como muestra el cuadro 2, la situación no era muy distinta. La percepción de esta realidad queda a veces oscurecida o, cuando menos, difuminada por la presencia de una gran masa de pastores, que se contaban por millares. Muchos de ellos poseían algunas cabezas de ganado merino, pero no se les puede considerar por ello ganaderos en el estricto sentido de la palabra, ya que carecian de posesiones propias y no podian disponer libremente de la lana de sus ovejas. Su condición de pequeños propietarios la debian a la excusa, el hato de ganado que, como complemento de

is Hacia 1664, la Junta de la Universidad solicito una real provision que salvaguardase los pastos arrendados por los concejos de la posesión mesteña (AHPSo. 3437, UT, 13). Para alusiones a la aplicación de la posesión en los agostaderos sorianos vid., por ejemplo, AHPSo, Protocolos, 2692 (4572, ff. 146-147), 2837 (4870, f. 170), 1041 (1607, f. 263). Sobre la posesión de los ganados del conde de Fuerteventura en agostaderos concejiles del Ducado de Medinaceli, AHN, Consejos, leg. 27938, exp. 8.

19 Diago (1994a). 


\section{CUADRO 2}

Estructura de la propiedad del ganado trashumante en varias jurisdicciones sorianas (c. 1752)

\begin{tabular}{|c|c|c|c|c|c|}
\hline Tamaño de la cabaña (cabezas) & $\begin{array}{l}\text { Numero de } \\
\text { propietarios }\end{array}$ & $\mathscr{0}$ & $\begin{array}{l}\text { Numero de } \\
\text { cabezas }\end{array}$ & $\%$ & $\begin{array}{c}\text { Tamaño } \\
\text { medio }\end{array}$ \\
\hline \multicolumn{6}{|l|}{ Tierra de Soria } \\
\hline$>10.000 \ldots \ldots$ & 3 & 0,66 & 44.991 & 18,38 & 14.997 \\
\hline $3.001-10.000$ & 21 & 4,65 & 107.377 & 43,87 & 5.113 \\
\hline $1.001-3.000 \ldots \ldots \ldots \ldots \ldots \ldots$ & 29 & 6,42 & 51.862 & 21,19 & 1.788 \\
\hline $251-1.000 \ldots \ldots \ldots \ldots \ldots \ldots \ldots \ldots$ & 37 & 8,18 & 19.595 & 8,00 & 530 \\
\hline$<250 \ldots \ldots$ & 362 & 80,09 & 20.947 & 8,56 & 58 \\
\hline Totales $\ldots \ldots \ldots \ldots \ldots \ldots$ & 452 & 100,00 & 244.772 & 100,00 & 542 \\
\hline SIN DFTtRMINAR * $\ldots$ & & & 27.081 & & \\
\hline Totai. trashumante $\ldots \ldots \ldots$ & & & 271.853 & & \\
\hline \multicolumn{6}{|l|}{ Tierra de Agreda } \\
\hline$>10.000 \ldots \ldots \ldots \ldots \ldots \ldots \ldots \ldots$ & 3 & 12,00 & 37.036 & 44,18 & 12.345 \\
\hline $3.001 \cdot 10.000 \ldots \ldots \ldots \ldots \ldots \ldots$ & 4 & 16,00 & 26.844 & 32,02 & 6.711 \\
\hline $1.001-3.000 \ldots \ldots \ldots \ldots \ldots \ldots$ & 10 & 40,00 & 16.348 & 19,50 & 1.635 \\
\hline $251.1 .000 \ldots \ldots \ldots \ldots \ldots \ldots \ldots$ & 5 & 20,00 & 3.442 & 4,11 & 688 \\
\hline$<250 \ldots \ldots \ldots \ldots \ldots \ldots$ & 3 & 12,00 & 161 & 0,19 & 54 \\
\hline Totalles $\ldots \ldots \ldots$ & 25 & 100,00 & 83.831 & 100,00 & 3.353 \\
\hline SIN DETERMINAR * $\ldots$ & & & 363 & & \\
\hline TOTAL TRASHUMANTE ......... & & & 84.194 & & \\
\hline \multicolumn{6}{|l|}{ Tierra de San Pedra Manrique ** } \\
\hline$>10.000 \ldots \ldots \ldots \ldots \ldots \ldots$ & - & - & - & - & - \\
\hline $3.001-10.000$. & 8 & 1,88 & 38.399 & 44,53 & 4.800 \\
\hline $1.001-3.000 \ldots$ & 5 & 1,17 & 7.946 & 9,22 & 1.589 \\
\hline $251-1.000 \ldots \ldots$ & 35 & 8,22 & 13.229 & 15,34 & 378 \\
\hline$<250 \ldots \ldots \ldots$ & 378 & 88,73 & 26.654 & 30,91 & 71 \\
\hline Totales $\ldots \ldots \ldots$ & 426 & 100,00 & 86.228 & 100,00 & 202 \\
\hline SIN DETERMINAR * $\ldots \ldots \ldots \ldots$ & & & - & & \\
\hline Total trashumante . . . . . . . & & & 86.228 & & \\
\hline
\end{tabular}

* Ganado cuya propiedad no especifican las respuestas a la pregunta 20*, en casi todos los casos por estar muy repartido entre ganaderos «de corto númerow.

** Se incluye, junto al lanar, el ganado cabrio que trashumaba.

FUENTE: AHPSo, Catastro de Ensenada, respuestas a la pregunta $20^{2}$ del Interrogatorio General. Los datos relativos a San Pedro Manrique, procedentes de la misma fuente, están tomados de Alcalde (1993), t. I, pp. 464 y 466, reelaborados. 
su salario y a cambio de la lana que producia, podian mantener en los pastos de la cabaña para la que trabajaban. La suya era, pues, una propiedad subordinada y dependiente, al igual que su posición dentro de la institución mesteña, en cuyas juntas sólo podian participar quienes poseian más de 150 cabezas ${ }^{20}$.

La concentración de la propiedad no sólo era social sino también espacial. En la Tierra de Soria, dejando a un lado la capital (donde entre 13 ganaderos poseian un tercio de todo el ganado trashumante de la jurisdicción), sólo en 24 pueblos, de los más de 150 que formaban parte de ella, habia más de 1.000 cabezas de ganado trashumante, y, de ellos, tan sólo en 5, más de 10.000 . Dentro de la Tierra de Soria, muchos pueblos serranos, o próximos a los lugares de residencia de los grandes ganaderos, se habian especializado en la provisión de mano de obra pastoril a las grandes cabañas.

Para entender cabalmente la composición social de la Mesta en las sierras es preciso subrayar dos distinciones fundamentales: la primera entre mesteños estantes y trashumantes y la segunda, dentro de los trashumantes, entre ganaderos y pastores. Esta última venía marcada no sólo por el desigual tamaño de sus propiedades sino, sobre todo, por la distinta posición que unos y otros ocupaban en las relaciones de producción establecidas dentro del mundo de la trashumancia. Por lo que se refiere a los pastores, a los que sólo la excusa convertía en pequeños propietarios, es evidente que hay una correlación entre el tamaño de sus piaras y el oficio pastoril (cuadro 3): a mayor cualificación, medida por el importe de la soldada, menor era el número de los no propietarios y mayor el de cabezas de ganado que, como término medio, tenian los que sí lo eran. De modo que si los pastores sólo eran propietarios en cuanto asalariados, la importancia de su propiedad dependía de la posición que ocupaban en la jerarquia pastoril. No obstante, dado que la contratación de pastores por parte de los mayorales se realizaba de forma verbal, es difícil saber si todas las cabezas que aquéllos poseian formaban parte de la excusa o si sólo una parte de las mismas gozaban gratuitamente de los pastos arrendados por sus amos, debiendo pagar por las yerbas que consumían las demás. Un rasgo común a la inmensa mayoria de las piaras de los pastores, que subraya la subordinación de éstos como propietarios, era el de estar compuestas, casi exclusivamente, por ovejas, corderos y, en su caso, cabras, siendo contadas las que incluian algún carnero.

20 Esta cifra aumentó a 500 entre 1736 y 1767 , probablemente coincidiendo con el periodo en que más proliferaton los pequeños propietarios serranos. 


\section{CUADRO 3}

Tamaño medio de las piaras pastoriles, según el oficio de su propietario, en tres pueblos de la Tierra de Soria (Gallinero, La Póveda y Valdeavellano), c. 1752

\begin{tabular}{|c|c|c|c|c|c|}
\hline Oficio & $\begin{array}{l}\text { Soldada * } \\
\text { (reales) }\end{array}$ & $\begin{array}{l}\text { Pastores } \\
\text { sin ganado }\end{array}$ & $\begin{array}{c}\text { Pastores } \\
\text { con ganado }\end{array}$ & $\begin{array}{c}\text { \% de pastores } \\
\text { con ganado } \\
\text { propio }\end{array}$ & $\begin{array}{l}\text { Cabezas por } \\
\text { propietario }\end{array}$ \\
\hline Mayorales .............. & 1.172 & 0 & 3 & 100,00 & 214 \\
\hline Rabadanes ............. & 641 & 6 & 57 & 90,48 & 53 \\
\hline Zagales ....... & 630 & 11 & 58 & 84,06 & 43 \\
\hline Ayudadores. & 564 & 9 & 15 & 62,50 & 32 \\
\hline Total. & & 26 & 133 & 83,65 & \\
\hline
\end{tabular}

* Incluye el salario en metalico mas la costa o manutención.

FufNTE: AHPSo, Catastro de Ensenada, asientos particulares.

Dentro de los ganaderos en sentido estricto, cabría, a su vez, distinguir: a) los grandes ganaderos, con cabañas por encima de las 3.000 cabezas y cuyos ingresos en las sierras procedian, fundamentalmente, de la lana de sus rebaños (véase cuadro 4), aunque en no pocos casos también poseían en ellas dilatados patrimonios tcrritoriales, en parte constituidos en función de sus intereses pecuarios; y b) los pequeños y medianos ganaderos independientes, que trashumaban por su cuenta 0 incorporaban sus rebaños en régimen de aparceria a otras cabañas mayores. Entre los primeros destacaban los miembros de la nobleza titulada (cuadro 5), cuya residencia en Soria o en Ágreda sólo perseguia el acceso gratuito a los pastos de verano que les garantizaba la vecindad serrana ${ }^{21}$; el resto eran, por lo general, hidalgos o dones. Los principales problemas de los pequeños y medianos ganaderos independientes, más abundantes en las tierras de Yanguas y San Pedro Manrique que en las de Soria o Ágreda, se relacionaban con el acceso a los pastos de invierno y su financiación. Los serranos solian pagar el importe de las yerbas invernales en el momento de emprender el camino de retorno acañada arriba», es decir, antes del esquileo y, en consecuencia, antes de la venta de la lana ${ }^{22}$. La falta de liquidez obligaba a muchos a contraer préstamos contra la garantía del ganado que conllevaban la venta anticipada de sus vellones, por un determinado número de cortes, a un precio inferior al que se pagaba por las grandes pilas ${ }^{23}$.

${ }^{21}$ Durante las décadas finales del siglo xviI y las primeras del $\mathrm{xIx}$, los nobles titulados fueron desapareciendo de las sierras conforme decaían sus explotaciones trashumantes.

22 Pereira (1992), p. 14.

${ }^{23}$ Calatayud (1761), pp. 7-9, se refiere a esta modalidad de compraventa de lana y a la rela- 
Por otro lado, sus costes fijos eran proporcionalmente mayores que para las grandes explotaciones, de modo que los beneficios por cabeza guardaban, por lo general, una relación directa con el tamaño de la cabaña. Como veremos, las condiciones relativamente favorables de que gozaron estas cabañas independientes de mediana entidad durante la primera mitad del siglo cambiarian bruscamente a finales de la década de 1760 .

\section{CUADRO 4}

Composición de los ingresos brutos anuales que generaban las propiedades de algunos grandes ganaderos en la Tierra de Soria (c. 1752)

\begin{tabular}{|c|c|c|c|c|c|}
\hline Ganadero & $\begin{array}{l}\text { Producto } \\
\text { agricola } \\
\text { (en reales) }\end{array}$ & $\%$ & $\begin{array}{l}\text { Producto } \\
\text { ganadero } \\
\text { (en reales) }\end{array}$ & $\%$ & $\begin{array}{c}\text { Total } \\
\text { (en reales) }\end{array}$ \\
\hline Conde de Fuerteventura & 995 & 0,46 & 217.350 & 99,54 & 218.345 \\
\hline Conde de Gómara ........ & 117.854 & 38,35 & 189.487 & 61,65 & 307.341 \\
\hline Marqués de Zafra . & 28.738 & 21,73 & 103.529 & 78,27 & 132.267 \\
\hline Marqués de Vadillo & 118.194 & 60,25 & 77.982 & 39,75 & 196.176 \\
\hline
\end{tabular}

FUENTE: AHPSo, Catastro de Ensenada, asientos particulares.

\section{CUADRO 5}

Nobles titulados entre los mayores ganaderos de las sierras sorianas, bacia 1752

\begin{tabular}{|c|c|c|}
\hline Título & Cabezas & Vecindad \\
\hline Marqués de Velamazän. & 15.900 & Ágreda \\
\hline Conde de Fuerteventura $\ldots \ldots \ldots \ldots$ & 15.772 & Soria \\
\hline Conde de Gómara ................ & 14.419 & Soria \\
\hline Conde de Villarrea $\ldots \ldots \ldots \ldots$ & 10.876 & Ágreda \\
\hline Marquesa viuda de Velamazán .... & 10.260 & Agreda \\
\hline Marquesa de Falces $\ldots \ldots \ldots \ldots \ldots$ & 9.835 & Ágreda \\
\hline Marqués de Zafra ... & 7.767 & Soria \\
\hline Marqués de Vadillo ............... & 6.346 & Soria \\
\hline Conde de Coruña $\ldots \ldots \ldots \ldots \ldots$ & 5.362 & Ágreda \\
\hline
\end{tabular}

FUENTE: AHPSo, Catastro de Ensenada, respuestas al Interrogatorio General y asientos particulares.

ción que guardaba el precio de la lana con el tamaño de la pila, relación lógica en la medida en que reflejaba el desigual coste que para los compradores suponia su recogida. Tomo esta observación de Llopis (en prensa), p. 8 y nota 46. 
Las grandes explotaciones vertebraban, pues, la trashumancia soriana: no sólo reunian el grueso del ganado y acaparaban los mejores pastos, sino que, además, de ellas dependia la mayoria de los demás propietarios, unos como pastores, como asalariados, es decir, integrados funcionalmente en las mismas, y otros - una parte de los pequeños o medianos ganaderos- en régimen de aparcería. Como elemento de contraste, conviene senalar que la propiedad del ganado lanar estante, vinculado a las explotaciones agricolas, estaba mucho más repartida, según se advierte en el cuadro 6 , confeccionado sobre una muestra. No en vano su función económica y social era muy distinta de la del trashumante.

\section{CUADRO 6}

Estructura de la propiedad del ganado estante en el sexmo de Lubia (Tierra de Soria, 1765)

\begin{tabular}{|c|c|c|c|c|c|}
\hline Tamaño del rebaño (cubezas) & Propietarios & $\%$ & Cabezas & $\%$ & $\begin{array}{c}\text { Tamaño } \\
\text { medio }\end{array}$ \\
\hline$>500 \ldots$ & 2 & 0,59 & 1.360 & 4,98 & 680 \\
\hline 301.500 & 13 & 3,81 & 4.983 & 18,24 & 383 \\
\hline $101-300$ & 66 & 19,35 & 12.066 & 44,17 & 183 \\
\hline$<100 \ldots$ & 260 & 76,25 & 8.909 & 32,61 & 34 \\
\hline Totales ... & 341 & 100,00 & 27.318 & 100,00 & 80 \\
\hline
\end{tabular}

FUfNe: AHN, Mesta, libro 282.

\section{LA LEGISLACIÓN DE PASTOS DE LA DECADA DE 1760 Y SUS EFECTOS}

La real provisión de 3 de noviembre de 1767, por la que se determinó la tasación y el reparto de los pastos de propios y arbitrados de los pueblos entre sus vecinos, dejando a disposición de los forasteros sólo los «sobrantes», marcó un punto de inflexión en la evolución de la trashumancia serrana ${ }^{24}$. Para las cabañas sorianas, sus efectos se dejaron sentir tanto en los invernaderos

${ }^{24}$ Brieva (1828), pp. 130-132. A esta seguiria la real provisión de 26 de mayo de 1770 , recogida en la Novisima Recopilación (ley XVII, tit. XXV, lib. VII), que cerraba una decada de tanteos legislativos, si bien aún sufrió algunas modificaciones durante los años siguientes. 
como en los agostaderos, puesto que su ámbito de aplicación, inicialmente restringido a los pueblos extremeños, se amplió, por otra de 18 de marzo de 1768, a todo el reino. En Extremadura, muchos ganaderos modestos, cuyos rebaños tenían posesión en dehesas de propios, fueron desplazados de las mismas ${ }^{25}$, viéndose obligados bien a buscar pastos alternativos en dehesas particulares, cuyos precios crecieron durante la década siguiente ${ }^{26}$, bien a ajustar el tamaño de sus cabañas a la cabida de sus ahora menguadas posesiones o a en. viar parte del ganado a la invernada «a sus aventuras», es decir, sin destino seguro y conocido. Aumentaron, pues, para ellos las dificultades para encontrar pastos, los costes de explotación y, también, los riesgos ${ }^{27}$. Aunque sus efectos en los invernaderos fueron, sin duda, los más importantes, la real provisión de 3 de noviembre de 1767 también repercutió en los agostaderos, donde la casi totalidad de los pastos arrendados eran de carácter concejil. De hecho, en la Tierra de Soria la legislación carolina sobre pastos vecinales habia empezado a surtir efecto desde su misma disposición inaugural, la real provisión de 25 de noviembre de 1761 , reiterada en 1765 , en virtud de la cual la posesión mesteña dejaba de ser aplicable a los pastos arbitrados con facultad real.

Una providencia del Consejo de 20 de abril de 1761 habia clasificado los pastos de los pueblos en tres categorias: propios apropiados, comunes arbitrados con facultad real y comunes de común aprovechamiento. Los últimos eran aquellos en los que todavía regia un aprovechamiento estrictamente comunal, en tanto que los demás estaban sujetos a arrendamiento, por ser bienes de propios o por gozar el concejo de licencia real para ello. En relación con estos arrendamientos, para lo sucesivo, se disponian dos cosas: primero, que se realizasen mediante «público pregón» y «al mejor postor», y, segundo, que se diese preferencia en los mismos a los vecinos ganaderos; lo cual, evidentemente, chocaba con el privilegio de posesión, que quedaba virtualmente anulado en los pastos concejiles. Las subastas, al introducir la competencia, venian a favorecer los intereses económicos de los concejos, al tiempo que la preferencia vecinal, dada la concentración geográfica de la propiedad trashumante, anteponía, en princi-

${ }^{25}$ Linares (1995), p. 106: en el partido de Llerena adesde 1767, la presencia trashumante en los pastizales del patrimonio municipal se reduce drasticamente en favor de los ganaderos de la tierra». Agradezco a Antonio Miguel Linares el haberme proporcionado una copia de su trabajo antes de que fuera publicado.

26 Melón (1989), pp. 197-199 y ss;; Pereira, Rodriguez Grajera, Melon (1992), pp. 469-470.

27. En 1780, un ganadero de Vinuesa, propietario de una cabaña de 2.050 ovejas y 70 cabras, declaró que en Extremadura sólo disponía de pastos seguros, en dehesas de Alcántara, para 600 cabezas, quedando las restantes «espuestas a la contingencia de valdios u algún acogimiento eventual», por haber sido adespojadas» de sus pastos en distintas villas (AHN, Consejos, leg. 7078). 
pio, las necesidades de pastos de los estantes, es decir, de los labradores, a las de las explotaciones ganaderas. Las protestas de la Mesta obligaron a rectificar la providencia de 20 de abril (por real provisión de 25 de noviembre), en el sentido de limitar su aplicación a los pastos arbitrados con facultad real, es decir, a los de naturaleza originariamente comunal, salvaguardando la posesión en los de propios y, también, en los sobrantes de dehesas boyales ${ }^{28}$. Aunque en los agostaderos sorianos los pastos arbitrados con expresa facultad real eran pocos, inmediatamente se alzaron voces reclamando tal condición para los que arrendaban los concejos, cuyo principal componente eran las rastrojeras.

Entre los interesados en sustraer los agostaderos concejiles de la posesión mesteña se contaban, en primer lugar, los labradores y ganaderos estantes. Por entonces, las roturaciones avanzaban en la Tierra de Soria, como en otras partes de Castilla, a costa de los baldios, lo cual implicaba que, en tanto se siguiesen arrendando los rastrojos, la cantidad de pastos a disposición de las explotaciones agrícolas tendería a ser cada vez menor, justo cuando estaban aumentando sus necesidades de abono y de ganado de labor, ganado que no siempre podia encontrar acomodo en las viejas dehesas boyales. La Junta de la Universidad se constituyó, una vez más, en portavoz y representante de las comunidades rurales. En 1762 intentó, incluso, forzar la devolución de los rastrojos a un aprovechamiento estrictamente comunal, es decir, a la situación en que se encontraban en el siglo xvi. Ciertamente sin éxito, ya que los concejos difícilmente podian renunciar a la que, en conjunto, constituia su principal fuente de ingresos ${ }^{29}$. Fracasada esta postura «maximalistam, la Junta centró sus esfuerzos en lograr la aplicación al ámbito soriano de las disposiciones que sobre aprovechamiento de pastos se sucedieron a partir de $1761^{30}$. En ello fue secundada por algunos ganaderos trashumantes, singularmente los menos be. neficiados por el reparto vigente de agostaderos.

A no pocos ganaderos, desde la perspectiva de sus intereses inmediatos, la anulación de la posesión en los agostaderos sólo podía favorecerles, ya que desbloquearía el sistema y haría posible una redistribución de pastos. En cuanto al efecto negativo que podía acarrearles la preferencia vecinal, reduciendo

\footnotetext{
${ }^{28}$ Se mantenian asi en vigor los reales decretos de 15 de mayo y 3 de octubre de 1746: Brieva (1828), pp. 69-72. Esta revisión de lo inicialmente dispuesto convertía la providencia del Consejo de 20 de abril de 1761 en un antecedente, parcialmente frustrado, de la real provisión de 3 de noviembre de 1767

29 La Junta consiguió una real provisión prohibiendo a los pueblos arrendar sus rastrojos "por el tiempo que devan estar cerrados y destinados para sus vezinos", pero no parece que surtiera ningún efecto (AHPSo, 3459, UT, 117).

"1" Para una análisis de esta legislación y de su incidencia en los invernaderos, vid. Marin Barrigucte (1989a v b).
} 
el volumen de pastos a disposición de las cabañas trashumantes, su alcance, en los términos en que la había establecido la provisión de 25 de noviembre, era limitado: primero, porque la preferencia debia ejercerse mediante tanteo, de modo que las pujas y la fijación de precios altos en los remates podía colocar los pastos fuera del alcance de la mayoría de los vecinos (salvo que éstos recurriesen a arrendamientos colectivos, como nos consta que hicieron en algún caso), y, segundo, porque el tanteo también podian reclamarlo los comuneros, condición que, en una interpretación amplia y ligada a la comunidad de pastos, como la que acabó imponiéndose ${ }^{31}$, incluia a todos los vecinos de la jurisdicción, $y$, por lo tanto, también a los ganaderos trashumantes. Además, los pastos que liberaría el desalojo de los trashumantes no "comuneros» podrian compensar la pérdida de los que absorbiesen los estantes. Los mayores perjudicados serian los ganaderos «extraños» que se habian infiltrado en los agostaderos concejiles en el transcurso del siglo xvit, y que, con la posesión, perderian, por completo, el acceso a los pastos de la Tierra de Soria. No obstante, algunos ganaderos sorianos defendian, por encima de cualesquiera otras consideraciones, la necesidad de respetar en su integridad los privilegios mesteños, incluso para los forasteros ${ }^{32}$.

El problema en términos juridicos era si las disposiciones de 1761 y subsiguientes podían aplicarse a las rastrojeras, lo que, a su vez, dependia de que se les reconociese o no el carácter de pastos arbitrados con facultad real, es decir, de una decisión, en último término, «politica». Al margen de ello, hay sobrados indicios de que la presión de concejos y vecinos para recuperar el control de sus pastos había comenzado bastante antes de que se promulgase la provisión de 20 de abril de $1761^{33}$. De modo que ésta actuó, sobre todo a partir de 1765 - año en que fue reiterada-, como un mero catalizador para el desencadenamiento de una conflictividad latente. Un buen ejemplo lo constituye el caso de la rastrojera de Boñices, cuyo concejo, que ya habian intentado sin éxito en 1759 desahuciar al arrendatario, la volvió a sacar a subasta en el mismo verano de 1761 . El pleito subsiguiente dio lugar, en 1764, a la primera sentencia que conocemos favorable a la preferencia vecinal y a la anulación de la posesión en las rastrojeras ${ }^{34}$.

3 Una real provisión de 21 de abril de 1778 aclaró que por comuneros «se entendian aquellos pueblos que entre si tenian comunidad de pastos en los que fuesen de libre aprovechamiento comun (AHN, Consejos, leg. 1091, exp. 19).

32 AHPSo, 3439, UT, 26.

"Sabemos, por ejemplo, que hacia 1754 varios pueblos del Ducado de Medinaceli habian intentado, sin éxito, desahuciar de sus agostaderos al conde de Fuerteventura, «a persuasión $e$ in flujo de algunos particulares ganaderos de ganado churrow (AHN, Consejos, leg. 27938, exp. 8). Alusiones a conflicros parecidos en la Tierra de Soria, en AHN, Consejos, leg. 42920, f. $39 \mathbf{v}^{\circ}$.

i4 AHN, Consejos, leg. 28597, exp. 5. 
El conflicto se inició, asi, en forma de casos particulares, adoptando alcance general cuando la Junta de la Universidad asumió la representación colectiva de todos los pueblos de la Tierra. Las actuaciones legales fueron acompañadas de una intensa conflictividad. Hubo encarcelamiento de alcaldes y vecinos de los pueblos que intentaban desahuciar a los ganaderos y peticiones de éstos de que se les amparase en sus posesiones, si era preciso, con «auxilio militar» ${ }^{35}$. La sentencia definitiva, dada en sala de mil y quinientas en junio de 1768 , fue plenamente favorable a las pretensiones de la Universidad al reconocer la preferencia de vecinos y comuneros —en este orden - por encima de la posesión ${ }^{36}$. En realidad, cuando se pronunció, la sentencia era ya innecesaria, puesto que la real provisión de 18 de marzo de ese mismo año había hecho extensiva a todo el reino la de 3 de noviembre de 1767, de contenido más radical. Durante los años siguientes muchos concejos, estimulados por la Junta de la Universidad, desahuciaron a los arrendatarios de sus agostaderos. Se calculó que entre 60.000 y 80.000 cabezas de ganaderos «extraños» tuvieron que abandonar los pastos sorianos, al tiempo que se producia una amplia redistribución de agostaderos entre los avecindados en la jurisdicción. En los libros de acuerdos del Honrado Concejo, puede comprobarse cómo por estos años se multiplicaron los reclamos de posesión referidos a agostaderos concejiles ${ }^{37}$. Inicialmente, los nuevos arrendamientos se concertaron mediante subastas. La liberalización del sistema y la competencia entre los ganaderos de la jurisdicción por hacerse con los pastos que los foráneos iban dejando vacantes elevaron pronto los precios ${ }^{38}$. En semejantes condiciones, los estantes poco provecho podian sacar de la preferencia vecinal, de modo que pronto reclamaron que se aplicase la real provisión de 3 de noviembre de 1767, mucho más favorable para ellos en cuanto sustituía el tanteo por un sistema de tasa y reparto, que sólo dejaba a disposición de los rebaños trashumantes los pastos «sobrantes», una vez acomodado en cada pueblo el ganado local ${ }^{39}$.

La legislación sobre arrendamientos de pastos concejiles tuvo varias consecuencias a partir de 1768 , cuando, casi simultáneamente, se resolvió el pleito planteado por la provisión de 1761 y se hizo extensiva a las sierras la de 1767: 1) Concejos y vecinos recuperaron, en parte, el control sobre sus pastos -más

\footnotetext{
"Asi ocurrió, por ejemplo, en los casos de Boñices (vid nota anterior) y Garray (AHPSo, 3439, UT, 26).

36 AHPSo, 3439, UT, 26.

3 AHN, Mesta, libro 518. La documentación local confirma, abundante y contundentemente, esta oleada de desahucios.

38 AHPSo, Audiencia, fondos en proceso de catalogación.

de Aragon preferencia vecinal también se reclamo, frente a riberiegos sorianos, en algunos pueblos
} 
necesarios para ellos conforme avanzaban los roturaciones-, desplazando de los mismos a una parte del ganado trashumante. El resultado fue una parcial reasignación de recursos entre las explotaciones agrícolas y las trashumantes, cuya magnitud no es posible determinar con la información de que disponemos. 2) Se operó una amplia redistribución de pastos entre las cabañas trashumantes, en un doble sentido: a) entre los ganaderos de las distintas jurisdicciones, al convertirse éstas en compartimentos estancos a efectos de aprove. chamiento de pastos, lógicamente, en perjuicio de aquellas en que mayor era el desequilibrio entre pastos disponibles y ganado existente; $y$ b) dentro de cada una de ellas en la medida en que, una vez anulada la posesión, los concejos pudieron actuar con cierta discrecionalidad a la hora de distribuir alos sobrantes», aun al precio de la tasa, entre los «comuneros» 40. 3) Los precios de los pastos subieron, aunque no parece que la subida fuera importante, ni tan siquiera considerando los bajos niveles de partida ${ }^{41}$ : primero, porque los ganaderos dentro de la jurisdicción en que tenían vecindad podian reclamar los «sobrantes» al precio de la tasa, pese a la resistencia de los pueblos a respetar ese derecho ${ }^{42}$; segundo, porque algunos disponian de instrumentos extraeconómicos para controlar los precios ${ }^{43}, \mathrm{y}$, tercero, porque los arrendamientos se celebraban, casi siempre, bajo la presión de las necesidades económicas de los concejos. El problema que se planteó en los agostaderos a partir de finales del decenio de los sesenta fue, pues, más de escasez relativa de pastos a disposi-

40 Los repartos se verificaban localmente, puesto que en jurisdicciones como la de Soria, con más de 150 pueblos, la realización de repartos generales planteaba dificultades técnicas insalvables. En 1769 el intendente ordeno, a petición de algunos ganaderos modestos, que se verificasc en ella tasación y reparto general de pastos, pero no parece que este sistema se impusiera.

4) No es fácil precisar la cuantia del aumento, dado que en los contratos de arrendamiento por lo general figura el importe del mismo, pero no el número de cabezas que el arrendatario podia introducir. Si nos guiamos por los contados contratos en que figuran ambos datos, el coste de los pastos de agostadero hacia 1770 se situaria entre 1,5 y 2,25 reales por cabeza. El precio de la rastrojera del lugar de Villaciervos aumentó entre 1767-1770 y 1791.1800 algo más de un 38 por 100 (Archivo Municipal de Villaciervos: «Libro de Actas, Cuentas de Propios, Arbitrios y Repartimientos»).

42 En 1770, el concejo de Villar del Rio (Yanguas) se quejaba de los perjuicios que le causaba el tener que renunciar a las subastas en beneficio de los comuneros que reclamaban sus pas tos por la tasa habiendo, como habia, ganaderos dispuestos a pagar mucho más por ellos (AHP. So, 2872, Protocolos, 4939, ff. 15.16). No era raro que algunos pueblos obligasen a los comuneros a concurrir a las subastas como si fuesen mextrañosw, lo que, lógicamente, provocaba las protestas de éstos; asi ocurrió en Renieblas en 1780 (AHN, Consejos. leg. 1091, exp. 19).

4) Por ejemplo, el marqués de Vadillo era un gran propietario en el sexmo de Tera, en algu. nos de cuyos pueblos buena parte de los vecinos eran renteros suyos. Esta actitud deferente, sin embargo, no se puede generalizar: en Gómara, algunos vecinos reclamaron preferencia en el arrendamiento de un agostadero sobre el que decía tener posesión el conde de Gómara, señor del lugar (AHPSo, 1180, Protocolos, 1810, ff. 254-255: 16 jul. 1799). 
ción de las cabañas trashumantes que de alza de los precios. Por otro lado, no se deben menospreciar los efectos negativos que, a corto plazo, tuvieron para el ganado los desahucios y el consiguiente trasiego de agostaderos.

Globalmente, la anulación de la posesión situó en mejores condiciones, a la hora de concertar arrendamientos, a los mayores ganaderos frente a los pequeños o medianos, dado que los concejos, siempre acuciados por su falta endémica de recursos, preferian ceder sus pastos, aunque fuera a menor precio, a quienes estaban en disposición de adelantar el importe de varios años de arriendo. Esta circunstancia permitió a algunos restaurar, en parte, la estabilidad en la disposición de pastos que habian perdido con la posesión ${ }^{44}$. En 1798 entre seis importantes ganaderos disponian en la Tierra de Soria de 53 pagos arrendados ${ }^{45}$. Paralelamente, se recrudeció la presión sobre los baldios, es decir sobre los pastos abiertos y gratuitos, hasta el punto de que algunos fueron de facto monopolizados por las grandes cabañas, que no dudaban en recurrir a "medios violentos» para alejar cualquier competencia ${ }^{46}$. El acaparamiento de pastos que se produjo en las sierras debió facilitar la concentración de la propiedad del ganado, reforzando una tendencia impuesta por la situación que los serranos atravesaban en los invernaderos. A finales de siglo y bajo la presión de las necesidades económicas del Ayuntamiento de Soria y de la Junta de la Universidad, se acotaron y arrendaron quintos en los baldios serranos, con cabida para 36.950 cabezas. El Consejo, al autorizarlos, estipuló su reparto entre los ganaderos que los solicitasen «por reglas de proporción, equidad y necesidad», es decir, atendiendo al número de cabezas que cada uno tenía sin acomodo en otros agostaderos. Estos acotamientos, aunque implicaban tener que pagar (un máximo de dos reales por cabeza) por pastos que hasta entonces ha. bian sido gratuitos, fueron bien recibidos por algunos medianos ganaderos, que vieron en ellos un instrumento eficaz para regular una competencia en la que, sin arbitraje externo, los «poderosos" jugaban con ventaja. Esta medida, en cualquier caso, se tomó ya tardíamente, puesto que los quintos fueron arrenda-

\footnotetext{
+4 La mayoria de los contratos hacen referencia a adelantos por parte de los arrendatarios a los concejos para que éstos pudieran hacer frente a distintas «urgencias». A titulo de ejemplo, podemos citar algunos de distintas fechas (entre corchetes): AHPSo, Protocolos, 965 (1491, ff. 69.70) [1714], 1035 (1600, ff. 803.804) [1723], 1051 (1621, ff. 293.294) [1747], 1269 (1741, f. 263) [1802], 1271 (1934, ff. 405.406) [1804]. La duración de los contratos oscilaba, por lo general, entre 2 y 9 años, siendo muy frecuentes por encima de 5 . Un caso de duración excepcional, que requirio, por ello mismo, de expresa facultad real, fue el del arrendamiento que en 1793 hizo el concejo de Villar del Campo de una dehesa y un pago de rastrojo, por 28 años, a cambio de los 22.769 reales que necesitaba para reparar la fuente y las cañerias del pueblo (AHPSo, 2221, Protocolos, 1874, ff. 221-224).

45 AHN, Consejos, leg. 29374, pieza 4.

to $\Lambda \mathrm{HN}$, Consejos, leg. 29374, pieza sin numerar, ff. 110-111.
} 
dos, por vez primera, en 1798. En los invernaderos la situación de los serranos también habia mejorado algo a raiz de la real orden de 26 de diciembre de 1784 , que los anteponia a los comuneros para el arriendo de pastos sobrantes, una vez acomodado el ganado de los vecinos ${ }^{47}$.

Por otro lado, la anulación de la posesión en los agostaderos se produjo en medio de un clima de creciente contestación contra el poder de la Mesta en las sierras, en el que desempeñó un importante papel la Junta de la Universidad, como representante de los labradores. Sus principales resultados fueron una merma de la capacidad de control del Honrado Concejo sobre las comunidades rurales (a partir de 1758 los pueblos de la Tierra de Soria quedaron fuera de las audiencias de los alcaldes entregadores) ${ }^{48}$ y la salida de los estantes serranos de la Mesta. Ésta, decretada por Campomanes en 1782, se debió, en buena medida, a las persistentes y reiteradas peticiones en dicho sentido de los labradores sorianos. Su pertenencia forzada a la Mesta sólo implicaba, en principio, la sujeción a la autoridad de los alcaldes de cuadrilla en tres aspectos: hacer mesta, señalar tierra a los ganados enfermos y conocer de despojos de posesiones entre hermanos mesteños; pero lo cierto es que tenía gravosas consecuencias económicas, como el pago de achaques o la contribución en los distintos repartimientos que aprobaba la institución. En 1765 y sólo en la Tierra de Soria unos 3.100 «hermanos» contribuyeron al repartimiento que dicho año realizó el Honrado Concejo, cuando entre ganaderos trashumantes, en sentido estricto, y pastores apenas sumarian una tercera parte de dicha cifra. El resto, a no dudarlo, eran labradores y campesinos con unas cuantas ovejas churras y en muchos casos ni tan siquiera eso: repasando la lista de los contribuyentes se encuentran muchos que sólo poseian ganado yeguar, vacuno o de cerda; no pocos una yunta y nada más ${ }^{49}$. En el mismo sentido, en 1773 , los alcaldes de cuadrilla incluyeron en las listas de hermanos solicitadas por el Consejo a todos los vecinos que tenían alguna cabeza de ganado, independientemente de su especie y, por supuesto, de que trashumasen o no.

Asi, cuando, en 1777, el presidente de la Mesta, don José de los Herreros, aclaró quiénes debian contribuir con dos mrs. por cabeza al repartimiento

47 Novisima Recopilacion, ley X, tit. XXVII, libro VII (también, nota 16 a la ley XVIII, tit. XXV, lib. VII). Brieva (1828), pp. 226-228.

48 AHPSo, 3449, UT, 66. En cuanto a la pérdida de autoridad de los alcaldes de cuadrilla son reveladoras las manifestaciones de uno de ellos en 1780: "se ba limitando el conozimiento de los alcaldes de Mesta tanto que no serbimos para nada, porque los ganaderos unos por burlarsen de otros y por mala idea con el alcalde, por azer su gusto, se ban a el corregidor y de hesa manera se habandona y desprezia la justizia de Mestas (AHN, Consejos, leg. 7078: relación del alcalde de la cuadrilla de San Miguel de Alcanoba).

14 AHN, Mesta, libro 282. 
acordado por el Concejo el 3 mayo de 1776 para sufragar los gastos del pleito con la provincia de Extremadura, no dudó en incluir, al tiempo que dejaba fuera a los «riberiegos de tierras llanas", a todos los propietarios de ganado de las sierras, «aunque no saliesen de sus pueblos, si se hallasen en el distrito de los alcaldes de quadrilla y jueces de Mesta y se rigieren y gobernaren por ellos» ${ }^{50}$. En esta ocasión los labradores redoblaron sus protestas con el decidido respaldo de la Junta de la Universidad, alegando que, como ganaderos estantes, no sólo no gozaban de los privilegios de la Mesta sino que padecian "una suma opresión de parte de los ganaderos trashumantes», de modo que contribuir a sufragar los gastos del pleito «seria contra las mismas cuadrillas más que a su favor" ${ }^{51}$. Los estantes de siete cuadrillas sorianas (y otras de las tierras de Almazán y Cuenca) se negaron a pagar, pese a las reiteradas tentativas de sus alcaldes por recaudar lo repartido ${ }^{52}$.

Campomanes, desde su llegada a la presidencia de la Mesta, se mostró receptivo a los argumentos de los estantes serranos, si bien el conflicto no se resolvió hasta 1782, cuando dictaminó, «por punto general», que, en lo sucesivo, no se obligara a ningún ganadero estante a pertenecer a la Mesta y se considerase sólo como hermanos a los que, voluntariamente, se inscribiesen en los libros de alistamiento que debian llevar los alcaldes de cuadrilla ${ }^{53}$. Acto seguido, los estantes sorianos se negaron a pagar los achaques, consiguiendo verse libres de ellos a partir de $1784^{54}$.

\section{MANIFESTACIONES DE LA «CRISIS" DE LA TRASHUMANCIA SERRANA}

En 1780 los alcaldes de las cuadrillas mesteñas elaboraron y remitieron al conde de Campomanes las relaciones que éste, como presidente de la Mesta, había ordenado hacer de los ganados y ganaderos con que contaba cada una de ellas. En dichas relaciones, varios alcaldes sorianos se lamentaron de la "suma escasez de ganados» que, a la sazón, padecian sus cuadrillas, fruto de la disminución del número de cabezas que habian experimentado «de 12 años a

AHPSo, 3458, UT, 107.

${ }^{51}$ AHPSo, 3471, UT, 137, ff. 284 y v": Libro de Actas y Acuerdos (en adelante LAA), s. 21 nov. 1777.

52 AHPSo, 3458, UI, 107. I.os cos de este conflicto son patentes en las relaciones de gana. deros elaboradas por los alcaldes de cuadrilla en 1781. En la de Fuentevieja, la resistencia de los estantes a ser inscritos en las listas fue particularmente tenaz (AHN. Consejos, leg. 7080).

"AHPSo, 3458, UT, 107.

'4 Ibidem; tambien, AHPSo, 3471, UT, 137, f. 434: LAA, s. 9 jun. 1784; y 1210. Protocolos, 1854, ff. $60 \cdot 61$. 
esta parte» 55 , y cuya causa, para ellos, no era otra que la pérdida, en los invernaderos, de posesiones en dehesas de propios. El alcalde de la cuadrilla del Río auguraba que la desolación se abatiria sobre las sierras si no se reintegraba a los ganaderos serranos sus «antiguos privilegios»: «hará treinta años - deciaque este pueblo [Castilfrio] tenía tantos ganados, poco más o menos, que la presente tienen entre los seis que componen esta cuadrilla" ${ }^{56}$. No exageraba al estimar las pérdidas. Si hacia 1752 un solo pueblo, Castilfrio, contaba con 45.650 cabezas, en 1780 la cuadrilla entera apenas superaba las 43.000: la disminución para ésta habia sido de un 44 por 100 entre ambas fechas. La cuestión es si estas apreciaciones, en principio de alcance local, reflejaban un fenómeno general.

No conocemos todavia con precisión cuál fue la evolución cuantitativa de las cabañas serranas durante la segunda mitad del siglo xvIII ${ }^{57}$. Los datos de que disponemos son insuficientes, de calidad desigual y, lo que es peor, no siempre concordantes. En consecuencia, no es fácil establecer si entre las repercusiones que la legislación de pastos de la década de 1760 tuvo sobre las cabañas sorianas hay que incluir una interrupción del crecimiento que éstas habian experimentado durante la primera mitad de la centuria o, incluso, una disminución, en términos agregados y con efectos a largo plazo, del número de sus efectivos trashumantes. Un primer acercamiento a esta cuestión puede ensayarse comparando las cifras del Catastro, elaborado hacia 1752, con las del mencionado recuento de 1780: el resultado es que entre ambas fechas el número de cabezas trashumantes parece haber disminuido, aunque de forma desigual, en la mayoría de las cuadrillas sorianas ${ }^{58}$. No obstante, esta compara-

"De tomar literalmente esta referencia cronologica, el inicio de las dificultades se situaria, exacta y significativamente, en 1768 .

56 Este alcalde se proponia a si mismo como ejemplo de las dificultades que venian atravesando los ganaderos serranos: «por reintegrar las pérdidas en la grangeria tenemos nuestras cassas sumamente desmenbradas, $y$, por exemplar, me pongo a mi mismo. En el año de sesenta y cuatro llevé a Estremadura 2.265 cavezas merinas lanares, oi sólo me allo con 854, siendo más de 1.500 las que he comprado en los años anteriores, en cuias compras y en las pérdidas de mis ganados he atrasado mi cassa en circunstancias de aver vendido una acienda raiz que tenia en el lugar de Renieblas de esta jurisdiccion en quince mil reales, haver grabado la labranza que cultibo en dos censos de catorce mil y dos cientos reales de principal, a fabor de la missa de doce de este pue blo, y allarme con bastantes deudas que superan a dos mil pesos, y consumido el fruto de lana de junio último; estos aogos suceden a m/uchos! ganaderos en las sierras, sin que vicio alguno se me pueda capitular ni censurar de mal administrador de mis ganados» (AHN, Consejos, leg. 7078).

"Acerca de la trayectoria de la trashumancia castellana en el siglo xvill, vid. Garcia Sanz. (1994) y (1978), y Llopis (1982). Para la evolución de una cabaña serrana a finales de la centuria, Herrero Hernandez (1992).

s* Por lo que se refiere a la Tierra de Soria, el numero de cabezas trashumantes habria disminuido en torno a un 25 por 100 . En las cuadrillas yangüesas, la disminución de ganado, según sus alcaldes, habia sido, entre 1768 y 1780 , wa la mitad" o, incluso, "a la tercera parten, si bien 
ción es insatisfactoria por varias razones: primero, ignoramos si los corderos fueron computados en la misma medida en uno y otro recuento; segundo, las relaciones de 1780 no son siempre claras al distinguir entre cabezas estantes y trashumantes, $y$, tercero, ignoramos cuál fue el impacto sobre las cabañas sorianas de la extraordinaria mortandad de ganado que, a causa de la sequía, se produjo en la invernada de 178059 . Además, aun soslayando los problemas de fiabilidad que plantean las cifras de 1780 , las fechas estan demasiado alejadas del núcleo de la crisis como para poder reflejarla adecuadamente.

La evolución de la parte del diezmo de lana fina correspondiente al obispo de Osma también corrobora, en primera instancia, la tesis de una acusada disminución del número de cabezas trashumantes en la segunda mitad del siglo: entre el quinquenio de 1754-1758 y el de 1781-1785, la media anual pasó de 3.204 a 1.551 arrobas ${ }^{60}$. Pero esta fuente tampoco está exenta de problemas: primero, las cifras proceden de certificaciones remitidas por el mismo obispado al Consejo de Castilla ${ }^{61}$; segundo, carecemos, precisamente, de los datos correspondientes al periodo 1758-1781, y, tercero, la disminución real seria, en cualquier caso, menor que la que refleja el cuadro 7 , ya que el excusado, que hacia mediados de siglo representaba en torno al 27 por 100 del total ${ }^{62}$, sólo aparece computado en las cifras anteriores a 1758. Además, los datos diezmales correspondientes a las dos úl. timas décadas del siglo, que reflejan una situación a medio camino entre el estancamiento y una ligera recuperación, no son del todo congruentes con el rápido incremento de la cantidad de lana lavada con destino a la exportación que, según otras fuentes, salió de la provincia en ese mismo periodo, y que pasó de

comparando las cifras del Catastro con las de 1780 el descenso entre ambos recuentos no es superior a un 12 o un 13 por 100 . La cuadrilla de Vinuesa, sin embargo, ateniéndonos a las cifras de 1752 y 1780 , si que habría experimentado una sensible teducción, de más del 34 por 100, porcentaje que, en este caso, se corresponde casi exactamente con el calculo de su alcalde: «y se atribuye la expresada disminucion a allarse los más sin posesion en Extremadura y tenerla antes en las dehesas de propios de varios pueblosw. En Almazản la reducción habria sido, más o me. nos, de la misma magnitud que en Vinuesa. En la cuadrilla de San Pedro Manrique, finalmente, las pérdidas habrian sido superiores al 50 por 100 , siempre considerando como términos de referencia 1752 y 1780 , siendo esta la única cuadrilla en la que se menciona una causa inmediata de mortandad del ganado, concretamente el haber comido estrepa (AHN, Consejos, legs. 7078-7080 y AHPSo, Catastro de Ensenada).

"El hecho de que no haya referencias a esta mortandad en las fuentes locales permitiria, en principio, minimizar su incidencia sobre los rebaños sorianos. Acerca de sus efectos en la cabaña del monasterio de Guadalupe, vid. Llopis (1982), pp. 43.44.

(1) AHN, Consejos, leg. 17024.

"1. No hemos podido contrastar la información de estas certificaciones con los libros originales, que, al parecer, no se han conservado en el archivo episcopal de Osma.

62 El volumen del excusado se ha calculado teniendo en cuenta el ganado trashumante de las mayores casas dezmeras de cada lugar (Archivo General de Simancas, Dirección General de Rentas, Libro del Mayor Hacendado, 608). 
una media anual de 76.058 arrobas entre 1782 y 1785 a 80.984 entre 1788 y 1792, y 94.460 entre 1795 y $1798^{63}$. Bien es cierto que parte de esa lana probablemente procedia del ganado estante. Finalmente, la hipótesis de la disminución no se compadece bien con la persistencia en las sierras de una intensa competencia por los pastos hasta finales de siglo, aunque a este respecto cabria considerar otros factores explicativos, como la disminución de la oferta de pastos que conllevó la roturación de baldios o un aumento de la demanda resultante del crecimiento del ganado estante. En definitiva, los datos expuestos permiten formular la hipótesis de que la legislación de pastos de los años sesenta marcó, en las sierras sorianas, un punto de inflexión en la evolución de la cabaña lanar, hacia el estancamiento o la disminución del número de cabezas trashumantes, si bien distan de ser concluyentes en cuanto a la generalidad y duración de sus efectos. De lo que caben menos dudas es de que dicha legislación propició una mayor concentración de la propiedad del ganado y su polarización entre las grandes cabañas y los pequeños propietarios, muchos de ellos en realidad pastores.

\section{CUADRO 7}

Diezmos percibidos por el Obispo de Osma *

\begin{tabular}{|c|c|c|c|c|c|}
\hline & Años & $\begin{array}{l}\text { Corderos } \\
\text { extremeños }\end{array}$ & $\begin{array}{l}\text { Medias } \\
\text { anuales }\end{array}$ & $\begin{array}{l}\text { Lanas } \\
\text { extremeñas }\end{array}$ & $\begin{array}{l}\text { Medios } \\
\text { anuales }\end{array}$ \\
\hline 1715.1719 & & 4.758 & 951,50 & 2.460 .75 & 492,00 \\
\hline $1738-1742$ & & 5.133 & $1.026,50$ & $2.050,00$ & 410,00 \\
\hline $1744 \cdot 1746$ & & 3.682 & $1.227,00$ & $1.864,50$ & 621,50 \\
\hline $1754-1758$ & & 6.050 & $1.210,00$ & $3.204,05$ & 640.81 \\
\hline 1781.1785 & & 2.413 & 482,50 & $1.551,36$ & 310,27 \\
\hline $1788-1792$ & & 2.795 & 559,00 & $1.901,84$ & 380,37 \\
\hline 1795.1799 & & 2.588 & 517,50 & $1.618,68$ & 323,74 \\
\hline $1823-1825$ & & 769 & 254,50 & 348,21 & 116,07 \\
\hline
\end{tabular}

* A partir de 1781-1785, los datos ya no incluyen el excusado. Fuente: AHN, Consejos, leg. 17024.

La nueva legislación afectó, en principio, a todas las cabañas con posesión en pastos de propios, tanto si eran grandes como pequeñas, pero las conse-

6) Los datos de lana lavada con destino a la exportación, en Taracena (1946), p 10, nota 22; González Enciso (1984), p. 56, y Rupérez Almajano (1987), p. 139. 
cuencias variaron en función de su tamaño. En lineas generales, las cabañas mayores fueron las que mejor resistieron el embate, al menos en la jurisdicción soriana (otro parece que fue el caso de Ágreda), donde los grandes ganaderos avecindados en la capital pasaron, entre 1752 y 1780 , de 14 a 11 en tanto que el ganado que poseían disminuyó ligeramente, de 83.655 a 80.265 cabezas. Estas cabañas, por lo que sabemos, tenian el grueso de sus yerbas invernales en dehesas de particulares, fuera del ámbito de aplicación de las nuevas leyes, $y$ en los agostaderos, aun perdiendo la posesión, pudieron seguir arrendando, como hemos visto, muchos pastos concejiles. Además, en caso de sufrir desahucios, en general tenian capacidad financiera suficiente para hacerse con pastos alternativos, aunque fuesen más caros que los que se veian obligadas a abandonar. De hecho, tomando como punto de referencia la situación en el momento de la confección del Catastro, las mayores cabañas (las que contaban con más de 10.000 cabezas) habian crecido a finales de siglo tanto en términos relativos como absolutos. No obstante, también hubo cabañas importantes entre las castigadas por la crisis. Como ejemplo, en 1780 el mayor ganadero de Vinuesa, con una cabaña de 7.336 cabezas ude señal» (incluyendo ovejas, cabras y caballerías) más 1.383 «de piaras», sólo contaba en Extremadura con yerbas para 5.080 cabezas, de modo que

el resto y sovrantes del ganado de dicha cabaña baja a sus abenturas adonde se puede acomodar, por falta de posesiones, por haverle quitado las que tenía en las dehesas boyales y de propios y arbitrios, por lo que esta cavaña a padezido y padeze grabisimos perjuicios, y se va minorando con eszeso ${ }^{64}$.

Por lo que se refiere a los pequeños propietarios, no parece que entre 1752 y 1780 disminuyera su número sino más bien todo lo contrario. Lo cual no significa que se mantuviera o aumentara el número de pequeñas explotaciones independientes sino el de pastores con excusa, fenómeno que, a su vez, debe vincularse al crecimiento de las grandes cabañas. A este respecto, es posible que la pérdida de posesiones fuese acompañada de una mayor dispersión de los pastos tanto en los invernaderos como en los agostaderos, incrementándose, en términos relativos, el número de pastores necesarios para conducir el ganado y, de paso, los costes de explotación. Por otro lado, la mayor difusión de la propiedad de ganado entre los pastores pudo obedecer a una estrategia de los ganaderos, a los que la aplicación de la fórmula de «lana por pastos» les permitia disponer de la lana de las piaras trasladando a los pastores los riesgos de

os AHN, Consejos, leg. 7078. 
pérdida del ganado por falta de yerbas donde acomodarlos; con la ventaja añadida de que cada pastor podía llevar sus ovejas durante el verano a los términos de su pueblo, esgrimiendo el derecho de vecindad a efectos de reparto de pastos. El cuadro siguiente, con datos de las cuadrillas de Valdecorral y Fuentevieja, compuestas básicamente por pastores, muestra cómo el aumento del número de pequeños propietarios fue acompañado por una disminución del tamaño medio de sus piaras. La pequeña propiedad se mantuvo o incluso aumentó en importancia relativa, pero a costa de la pérdida de independencia y de una disminución del número de cabezas por propietario.

\section{CUADRO 8}

Propietarios de menos de 250 cabezas en las cuadrillas de Valdecorral y Fuentevieja en 1752 y 1780

\begin{tabular}{|c|c|c|c|c|c|c|}
\hline \multirow{2}{*}{ Cuadrilla } & \multicolumn{2}{|c|}{1752} & \multicolumn{2}{|c|}{1780} & \multicolumn{2}{|c|}{$\begin{array}{l}\text { Tamaño medio } \\
\text { de las piaras }\end{array}$} \\
\hline & $\begin{array}{l}\text { Numero de } \\
\text { propictarios }\end{array}$ & $\begin{array}{l}\text { Numero de } \\
\text { cabezas }\end{array}$ & $\begin{array}{l}\text { Nuimero de } \\
\text { propietarios }\end{array}$ & $\begin{array}{l}\text { Numero de } \\
\text { cabczas }\end{array}$ & $\begin{array}{c}1752 \\
\text { (cabczas) }\end{array}$ & $\begin{array}{c}1780 \\
\text { (cabezas) }\end{array}$ \\
\hline Valdecorral & 114 & 6.248 & 144 & 5.389 & 43 & 37 \\
\hline Fuentevieja & 16 & 1.005 & 35 & 1.874 & 63 & 54 \\
\hline Toral ......... & 130 & 7.253 & 179 & 7.263 & 56 & 41 \\
\hline
\end{tabular}

FuENTES: AHPSo, Catastro de Ensenada y AHN, Consejos, legs. 7079.7080.

Fueron los medianos ganaderos, los dueños de cabañas entre 250 y $3.000 \mathrm{ca}$ bezas, los que más sufrieron los efectos de la nueva legislación. La pérdida de pastos fue para ellos especialmente grave en los invernaderos, por la amplitud que alcanzó y porque alli el recurso a los baldios, enviando el ganado «a sus aventuras», era una opción más problemática y arriesgada que en las sierras. Sabemos, por ejemplo, que hacia 1791 en el partido de Llerena los ganaderos serranos habian sido desalojados de, cuando menos, 32 de las 49 dehesas de propios en que pastaban cuarenta años antes ${ }^{65}$. Las alternativas eran recurrir a la aparcería o el acogimiento, acudir a las subastas de "sobrantes» vecinales o arrendar yerbas de particulares, y todas implicaban un incremento de los costes de explotación. La competencia y el acaparamiento que practicaban las grandes cabañas, tanto en los invernaderos como en los agostaderos, empeoraron la situacion. En

ns Linares (1995), p. 106. 
este sentido es conocida la representación suscrita en 1779 por 59 ganaderos sorianos, quejándose de la «mala calidad de pastos que tenian en sus pocas dehesas y agostaderos", y de que muchos se veian obligados a mantener su ganado en los baldios, por no poder alcanzar «las excesivas y exorbitantes pujas» que hacian los ganaderos poderosos ${ }^{\text {th. }}$. En este contexto, el deterioro de los términos de intercambio entre la lana fina y el trigo que se produjo entre 1763 y 178567 debió de afectar a las cabañas modestas en mayor medida que a las grandes explotaciones trashumantes.

Las respuestas de estos ganaderos a la crisis, cuando pudieron evitar la ruina, pasaron por la venta de sus rebaños y el abandono del negocio pecuario, su conversión en ganaderos estantes o la adopción de nuevas estrategias empresariales. Asi, en 1781 se fundó una Compañia de Ganaderos de las Provincias de Soria y Burgos, a la que se incorporaron muchos de ellos, con el propósito de, por un lado, lograr mejores precios por su lana al venderla conjuntamente, y por lo tanto en partidas mayores, lavada y excusando intermediarios, $y$, por otro, respaldarse mutuamente en materia de disponibilidad de crédito para pagos anticipados, ya que una de las funciones que cumplia la Compañia era la concesión de préstamos sobre la lana que cada uno aportaba a la misma. Intentaron, asi, compensar el aumento del coste de los pastos con una disminución de los costes financieros y, sobre todo, un aumento de los beneficios de la venta de la lana, introduciéndose en el ámbito de la comercialización. El fracaso de la Compañia, independientemente de los errores que pudieran cometerse en su gestión $y$ de las condiciones adversas en que tuvo que actuar (guerra contra la Convención), dice mucho de las dificultades que entrañaba la empresa. Pero el hecho de que, después de liquidada, se constituyera una nueva con los mismos fines implica que los pequeños y medianos ganaderos ya no podían afrontar aisladamente el negocio de la trashumancia. En cuanto a la conversión de ganaderos trashumantes en estantes, carecemos de información directa sobre el fenómeno. Pero es posible que tenga algo que ver con la creciente importancia que, durante la segunda mitad del siglo, adquirio la exportación de lana entrefina, lana que, segün Larruga, procedia en su mayor parte de "ganado merino quedado», si bien, a juicio de algunos ganaderos serranos, tal denominación sólo se utilizaba para extraer fraudulentamente lanas «bastas, burdas y ordinarias» ${ }^{6 *}$.

to Las citas de esta representación, que fue incorporada al Memorial ajustado de 1783, las tomo de Garcia Martin (1988). Sobre la discriminación que sufrian los pequeños ganaderos en los repartos vecinales de pastos, vid. el caso de Almarza en 1784-1785: AHPSo, 1218, Protocolos, 1868, ff. $63-64$ y $287-288$.

Q. Llopis (1982), pp. 51.52 .

os Larruga (1793), L. XXI, p. 124. Archivo Municipal de Soria, Sociedad Económica de Amigos del Pais, lege 10. 


\section{CUADRO 9}

Composición de las cabañas de más de 1.000 cabezas en 1752 y 1797-98 (Tierra de Soria) *

\begin{tabular}{|c|c|c|c|c|c|}
\hline Tamaño de las cabarias & $\begin{array}{l}\text { Númeno de } \\
\text { ganaderos }\end{array}$ & $\%_{0}$ & $\begin{array}{l}\text { Número de } \\
\text { cabezas }\end{array}$ & $\%$ & $\begin{array}{l}\text { Tamaño medio } \\
\text { de las cabuñas }\end{array}$ \\
\hline \multicolumn{6}{|l|}{1752} \\
\hline$>10.000 \ldots \ldots \ldots$ & 3 & 5,66 & 44.991 & 22,03 & 14.997 \\
\hline $3.001-10.000 \ldots$ & 21 & 39,62 & 107.377 & 52,58 & 5.113 \\
\hline $1.001-3.000 \ldots \ldots$ & 29 & 54,72 & 51.862 & 25,39 & 1.788 \\
\hline Total $\ldots \ldots \ldots$ & 53 & 100,00 & 204.230 & 100,00 & 3.853 \\
\hline \multicolumn{6}{|l|}{$1797-98$} \\
\hline$>10.000 \ldots$ & 6 & 16,22 & $111.771 * *$ & 56,36 & 18.628 \\
\hline $3.001 \cdot 10.000 \ldots \ldots \ldots \ldots \ldots \ldots$ & 8 & 21,62 & $47.549 * *$ & 23,98 & 5.944 \\
\hline $1.001-3.000 \ldots \ldots \ldots \ldots \ldots \ldots$ & 23 & 62,16 & $38.983^{\star *}$ & 19,66 & 1.695 \\
\hline Total ............... & 37 & 100,00 & $198.303 * *$ & 100,00 & 5.359 \\
\hline
\end{tabular}

* Es posible que los datos de 1752 estén ligeramente infravalorados en sus tramos inferiores, puesto que la fuente no permite, como se ve en el cuadro 2, distribuir la totalidad del ganado en función del tamaño de las cabañas. En cuanto a los de 1797.98, por el contrario, es posible que estén sobrevalorados ya que proceden de declaraciones de los propios ganaderos, a efectos de re. parto de quintos en baldios acotados.

** Incluyen, en algunos casos, piaras pastoriles y ganado cabrio.

Futntts: AHPSo, Catastro de Ensenada, respuestas al Interrogatorio General y AHN, Consejos, leg. 29374, pieza 4.

A finales de siglo, como refleja el cuadro 9, dentro de las grandes cabañas, las mayores habian crecido en número y en tamaño medio, ganando a la vez peso relativo. $\mathrm{Si}$ en 1752 sólo 3 contaban con más de 10.000 cabezas, en 1798 eran ya 6 las que superaban esa cifra. Algunas habian crecido espectacularmente, como la cabaña del marqués de Vadillo, que pasó de 6.346 cabezas en 1752 a 38.862 en $1798{ }^{69}$. Este es el caso más llamativo, pero no el único: entre 1752 y 1798 la cabaña del conde de Fuerteventura pasó de 15.772 a 21.650 cabezas, y la del conde de Gómara de 14.419 a 18.295 . Esta concentración de la propiedad se habia producido a costa de los estratos intermedios, puesto

69 AHPSo, Catastro de Ensenada, asiento particular; AHN, Consejos, leg. 29374. Las cifras de 1798 incluyen cabras y, seguramente, también las piaras pastoriles. En 1806 el inventario de los bienes de la marquesa de Vadillo incluia 27.664 cabezas (AHPSo, 1254, Protocolos, 1922). 
que el número de los pequeños propietarios también habia aumentado, si bien a finales de siglo la mayor parte de éstos no eran otra cosa que pastores con excusa. Grandes ganaderos y pastores se consagraron, asi, como los dos principales componentes de la trashumancia soriana. En este sentido, el intendente de Soria había informado en 1777 al Consejo:

La crianza, que consiste en cabañas de ganado lanar trashumante, está repartida en un centenar, quando más, de personas en toda la provincia, siendo el resto unos meros sirvientes de aquéllos, que apenas reciven un infimo salario con que atienden a sus necesidades, sin arbitrio a otros aprovechamientos para el cum. plimiento de sus respectivas obligaciones ${ }^{70}$.

\section{CONCLUSIONES}

La trashumancia soriana constituia en el siglo XvIII un caso relativamente peculiar en el contexto castellano. No tanto por la estructura de la propiedad del ganado, que reproducia fielmente el panorama general del reino, caracterizado por una notable concentración, cuanto por el sistema de aprovechamien. to de pastos que regia en las sierras sorianas. Éste permitia a las grandes cabañas autóctonas ejercer un control exclusivo sobre los baldíos de las estribaciones del Sistema Ibérico, vedando el acceso a los mismos a todos los ganaderos no avecindados en las sierras. Por otro lado, a partir de finales del siglo XVI, las cabañas trashumantes habían invadido los pastos comunales de las zonas cerealistas del valle del Duero, haciéndose con el aprovechamiento de algunas dehesas boyales y, sobre todo, desvirtuando una de las instituciones más inequivocamente comunales del campo castellano, la derrota de mieses. Este acaparamiento de pastos, consolidado mediante la aplicación del privilegio de posesión en los agostaderos que les eran arrendados por los concejos, fue acompañado por la firme instalación de la oligarquía ganadera en las principales instituciones de poder local, lo cual, combinado con los instrumentos de control mesteño, hizo de las tierras sorianas un espacio dominado por grandes propietarios trashumantes, en su mayoria nobles, avecindados en los principales núcleos urbanos del valle del Duero (Soria, Ágreda, Almazán). Las sierras les proporcionaban pastores y, lo que era más importante, pastos de verano gratis o a bajo precio gracias a la restricción de la competencia que resultaba de la aplicación combinada del privilegio de posesión y los derechos

${ }^{70} \mathrm{AHN}$, Consejos, leg. 902, exp. 12. 
de vecindad. Este era el panorama a mediados del siglo xvilI, reforzado si cabe en algunas jurisdicciones (como la Tierra de Soria) por la compra de los baldíos que los pueblos, estimulados por los grandes ganaderos, habian hecho a la Corona hacia 1739.

En suma, y con los datos de que disponemos en este momento, podemos concluir lo siguiente: 1) Una de las principales ventajas comparativas de las ex. plotaciones trashumantes sorianas radicaba en un sistema de aprovechamientos de pastos de verano que, combinando los derechos de vecindad, como criterio discriminador para el acceso a los baldíos de las sierras ibéricas y, el privilegio de posesión sobre las rastrojeras y otros pastos concejiles, ponia a su disposición amplias áreas de agostadero en condiciones sumamente ventajosas. 2) La propiedad del ganado estaba notablemente concentrada en las «sierras» y aunque había una multitud de pequeños propietarios entre los pastores, la suya era una propiedad dependiente, por cuanto no disponían de otros pastos de invernadero que los que les cedian los ganaderos para los que trabajaban, a los que a cambio, por regla general, entregaban la lana de sus ovejas. 3) La le. gislación sobre pastos concejiles del decenio de 1760 implicó para muchos ganaderos serranos la pérdida de posesiones. Sus principales efectos se dejaron sentir en los invernaderos extremeños, aunque también repercutió en las sierras, donde las comunidades rurales, reforzadas y cada vez mejor articuladas internamente gracias a una coyuntura agrícola favorable, utilizaron dichas leyes para recuperar una parte de los pastos vecinales que desde fines del siglo Xvı detentaban las explotaciones trashumantes, al tiempo que roturaban los mejores baldíos. Todo ello, en medio de un clima de fuerte contestación contra el poder de la Mesta y de progresiva erosión de sus mecanismos de control sobre los pueblos. 4) La incidencia de la nueva legislación de pastos sobre las cabanas trashumantes de las sierras fue desigual en función del tamaño de éstas. Las mayores fueron las menos afectadas y siguieron creciendo, al igual que el número de pastores con excusa empleados a su servicio, en tanto que muchas explotaciones independientes de menor entidad no pudieron sobreponerse a las pérdidas de pastos que sufrieron tanto en los invernaderos - sobre todo en éstos- $\rightarrow$ como en los agostaderos. Algunas de éstas, no obstante, quizá subsistieron como estantes. El resultado fue, en términos relativos, un reforzamiento de la concentración de la propiedad trashumante y una mayor polarización de la misma entre los grandes ganaderos y sus pastores. 5) Finalmente, aunque los datos no son concluyentes ni univocos, cabe mantener la hipótesis de que esta reestructuración de la propiedad pudo ir acompañada de un estancamiento o disminución, en términos agregados, de los efectivos trashumantes en las sierras sorianas. 


\section{BIBLIOGRAFIA}

AlCAlde Jimenez, J. M. (1993): «El régimen señorial en la provincia de Soria. Estructura y crisis. Siglos XVIII y XIX», Tesis Doctoral, Universidad de Zaragoza (en prensa).

Anes, G., y Garcia SANZ, A. (1994): Mesta, trashumancia y vida pastoril, Madrid, Junta de Castilla y León (Sociedad V Centenario del Tratado de Tordesillas).

Brieva, M. (1828): Colección de leyes, reales decretos y órdenes, acuerdos y circulares pertenecientes al ramo de la Mesta desde el año de 1727 al de 1827, Madrid.

Calatayud, P. de (1761): Tratados y doctrinas prácticas sobre ventas, y compras de lanas merinas, $y$ otros géneros; y sobre el juego de naypes, $y$ dados con un suplemento de veinte $y$ seis contratos, Toledo.

Diago Hernando, M. (1990): «Aprovechamiento de baldios y comunales en la Extremadura soriana a fines de la Edad Media», Anuario de Estudios Medievales, 20, pp. 413.434.

- (1993a): Soria en la Baja Edad Media. Espacio rural y economía agraria, Madrid, Editorial Complutense.

- (1993b): «El arrendamiento de pastos en las comunidades de villa y 'Tierra a fines de la Edad Media: una aproximación», Agricultura y Sociedad, 67, pp. 185-203.

- (1994a): «Grandes y pequeños ganaderos trashumantes en las sierras sorianas en el tránsito de la Edad Media a la Edad Moderna», Revista de Historia Económica, XII, 2, pp. 343.364.

- (1994b): «El aprovechamiento de pastos de verano en las comarcas ganaderas del Sistema Ibérico castellano en los siglos xv y xvi», Noticiario de Historia Agraria, 8 , pp. 43-65.

DiEz SAnz, E. (1995): La Tierra de Soria. Un universo campesino en la Castilla oriental del siglo XVI, Madrid, Siglo XXI.

GARCla Martin, P. (1988): «La crisis de la ganadería serrana en la Castilla del siglo xvill: el partido mesteño de Soria», Celtiberia, 74, pp. 291-307.

Garcis SAnz, A. (1977): Desarrollo y crisis del Antiguo Régimen en Castilla la Vieja. Economía y saciedad en tierras de Segovia de 1500 a 1814, Madrid, Akal.

- (1978): "La agonia de la Mesta y el hundimiento de las exportaciones laneras: un capitulo de la crisis del Antiguo Régimen en Españam, Agricultura y Sociedad, 6, pp. 284.316.

- (1980): «Bienes y derechos comunales y el proceso de su privatización en Castilla durante los siglos XVI y XVII: el caso de tierras de Segoviam, Hispania, 144, pp. 95.127.

- (1994): «El siglo XVIII: entre la prosperidad de la trashumancia y la critica antimesteña de la Ilustración (1700-1808)», en Anes y Garcia Sanz (1994).

Gonzalez. Enciso, A. (1984): “Industria textil y Sociedad Económica en Soria», Anales de Historia Contemporánea, 3, pp. 25.57.

Herrero Hernandez, M. de los A. (1992): «La decadencia de la ganaderia trashumante en la Sierra de Cameros (1780.1821)», Revista de Historia Económica, X, 2, pp. 201-212.

LARRU(i八, E. (1793): Memorias políticas y económicas sobre los frutos, comercio, fábricas y minas de España, con inclusión de los reales decretos, órdenes, cédulas, aranceles y ordenanzas expedidas para su gobierno y fomento, Madrid, tomos XXI-XXII.

LinAREs LuJAN, A. M. (1995): «De la apropiación del usufructo a la privatización de la superficie. Las tierras concejiles en la Baja Extremadura (1750-1850)m, Noticiario de Historia Agraria, 9, pp. 87-127. 
Llopis AgELAN, E. (1982): «Las explotaciones trashumantes en el siglo xvil y el primer tercio del xix: la cabaña del Monasterio de Guadalupe, 1709-1835m, en Gonzalo Anes (ed.), La economia española al final del Antiguo Régimen. I. Agricultura, Madrid, Alianza, pp. 1-101.

(1986): «El agro castellano en el siglo XvII: ¿depresión o reajustes y readaptaciones?", Revista de Historia Económica, IV, 1, pp. 11-37.

- (en prensa): «Medio siglo de una gran explotación trashumante: la cabaña merina del Monasterio de El Paular, 1680-1730m.

MARIN BaRRIGUETE, F. (1989a): "Los ilustrados, la Mesta y la trashumancia», en Estructuras Agrarias y Reformismo llustrado en la España del siglo XVII, Madrid, MAPA, pp. 763.784 .

- (1989b): «Reformismo y ganaderia: el Honrado Concejo de la Mesta en el reinado de Carlos III", en Actas del Congreso Internacional sobre "Carlos III y la Ilustración", vol. I («El Rey y la Monarquia»), Madrid, Ministerio de Cultura, pp. 569-586.

Melón Jimenez, M. A. (1989): Extremadura en el Antiguo Régimen. Economia y Sociedad en tierras de Cáceres, 1700-1814, Mérida, Editora Regional de Extremadura.

Pereira Iglesias, J. L. (1992): «La trashumancia y sus repercusiones económicas y sociales en zonas de invernadero: el caso de Extremadura». Comunicación presentada en el Seminario de Historia Económica: "Mesta, trashumancia y lana en la España Moderna» (Soria).

Pereira Iglesias, J. L.; Rodrigue. Grajera, A., y Melon Jimenez, M. A. (1992): «Evolución de los precios de los invernaderos de las dehesas extremeñas durante el Antiguo Régimen», en V. Cabrero, J. M. Llorente y otros: El medio rural español. Cultura, paisaje y naturaleza, Universidad de Salamanca, pp. 461-473.

Perez Romero, E. (1995): Patrimonios comunales, ganaderia trashumante y sociedad en la Tierra de Soria. Siglos XVIII y XIX, Junta de Castilla y León, Valladolid.

Ruperez Almajano, M.* N. (1987): La Sociedad Económica de Amigos del País de Suria (1777-1809). Estudio Institucionah Diputación Provincial, Soria.

Taracena Aciuirre, B. (1946): La Sociedad Económica Numantina de Amigos del País, Real Sociedad Vascongada de Amigos del Pais, San Sebastián. 